\title{
Ecological effects of ionic liquids on microbial activity of a soil and on tree seed
}

\section{germination}

\author{
I. Salgado $^{a *}$, T. Teijeiraa, J.J. Parajóa, M. Villanuevaa, R. Núñez ${ }^{\mathrm{b}}$, O. Reyes ${ }^{\mathrm{b}}$ \\ ${ }^{a}$ Applied Physics Department. Campus Vida. Santiago de Compostela University 15782 Santiago. Spain \\ ${ }^{b}$ Department of Cellular Biology and Ecology. Santiago de Compostela University 15782 Santiago. Spain \\ *Corresponding author: j.salgado.carballo@usc.es
}

Keyword: Ionic liquids, toxicity, soil microbial response, microcalorimetry, seed germination

\begin{abstract}
In this work the effect of addition of different doses of 1-butil-2,3-dimethylimidazolium trifluoromethanesulfonate on microbial activity of a soil under Pinus pinaster Aiton and on the seed germination of species of P. pinaster, Pinus sylvestris L., Pinus radiata D. Don and Eucalyptus globulus Labill were analyzed. Additionally, seed germination test were also applied to this IL after being subjected to heat treatment.
\end{abstract}

\section{Introduction}

Room temperature ionic liquids (RTILs) are considered one of the most promising green alternatives to molecular organic solvents. These compounds have currently become a major interest in both industrial and academic communities, due to the knowledge of the dependence of the properties of RTILs with the structure and its possibility of tuning. Lots of cations and anions can be combined to create ILs for a particular application. Most of these compounds have negligible vapor pressure and low flammability, important properties for improved safety compared to conventional organic solvents. In this context ILs seem to have an important role in 2020 horizon and ILs will be used for the production of substances of low toxicity and low persistence in the environment (environmental compatibility). These conditions seem feasible to consider the enormous potential of design LIs.

Despite the increasing number of papers that try to determine the toxic effects of ILs, the knowledge of their ecotoxicity and biodegradability is still an open question. The few studies that deal with it [1] provides that derived imidazolium ILs are those with lower biodegradability while pyridinium have greater potential for degradation. Likewise, ILs with anions [PF6] and [BF4] as well as being sensitive to hydrolytic processes are poorly biodegradable, while the acetate and sulfate anion appear to be more environmentally friendly.

In this work the effect of addition of different doses of 1-butil-2,3-dimethylimidazolium trifluoromethanesulfonate, $\left[\mathrm{C}_{4} \mathrm{C}_{1} \mathrm{C}_{1} \mathrm{Im}\right][\mathrm{OTf}]$, on microbial activity of a soil under Pinus pinaster Aiton and on the seed germination of species of P. pinaster, Pinus sylvestris L., Pinus radiata D. Don and Eucalyptus globulus Labill were analyzed. Plants have different phases of their biological cycle, and the most sensitive point of any external agent is germination. For this 
reason, ILs effects were tested on germination. Additionally, seed germination test were also applied with this IL after being subjected to a laboratory heat treatment.

\section{Material and methods}

\section{Chemical}

1-Butyl-2,3-dimethylimidazolium trifluoromethanesulfonate $\left(\left[\mathrm{C}_{4} \mathrm{C}_{1} \mathrm{C}_{1} \operatorname{Im}\right][\mathrm{OTf}]\right.$, CAS Number: 765910-73) was selected for this work. This IL was kindly provided by Merck KGaA. The specified mole fraction purity is higher than 0.98 . Figure 1 shows the chemical structure.

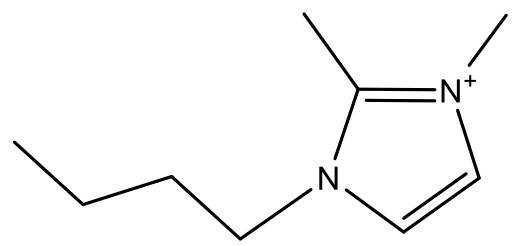<smiles>O=S(=O)([O-])C(F)(F)F</smiles>

\section{Figure 1: Chemical structure of 1-Butyl-2,3-dimethylimidazolium trifluoromethanesulfonate}

\section{Soil microcalorimetry}

The effect of the addition of four doses (10\%, $25 \%, 50 \%$ and $75 \%)$ on organic matter and microbial activity on Galician soil under P. pinaster Aiton was study by microcalorimetry.

A microcalorimeter Thermal Activity Monitor (TAM-III) TA-Instruments was used to determine the influence of the IL addition. Measurements were carried out in hermetically sealed $5 \mathrm{ml}$ stainless steel ampoules. Soil samples of $1 \mathrm{~g}$ size at water-holding capacity, treated with $0.2 \mathrm{ml}$ of a glucose solution in water with a concentration of $6.25 \mathrm{~g} / \mathrm{l}$ to activate the metabolism of soil microorganisms, were used as control [4]. The heat released by the microorganisms was recorded until the total consumption of glucose. Two replicates were carried for each case. From the data obtained in these experiments, the calculation of microbial growth was performed [5].

\section{Germination response}

Seed germination response was evaluated for five doses $(10 \%, 1 \%, 0.1 \%$ and $0.01 \%$ and control) of the selected IL in two different conditions, as supplied (Natural) and after a laboratory heat treatment (Degraded). For the IL degradation, a sample of the IL was heated in an oven at $200{ }^{\circ} \mathrm{C}$ during $24 \mathrm{~h}$. Seed germination test on the species P. pinaster, $P$. sylvestris ., $P$. radiata and E. globulus were carried out for both, degraded and no degraded IL. Initially, $4 \mathrm{ml}$ of each treatment were added to every Petri dish, and then were irrigated with distilled water to keep the seeds wet. Five replies with 25 seeds per Petri dish were incubated in a Phytotron (Climas AGP890) for every species and treatments [6]. Seeds were maintained for $16 \mathrm{~h}$ under 
light at $24{ }^{\circ} \mathrm{C}$ and in the dark for $8 \mathrm{~h}$ at $16{ }^{\circ} \mathrm{C}$ during 45 days, when the germination was completed in all the species [6]. The germination percentage was calculated from the data obtained at the end of 45 days.

\section{Statistical treatment}

The following transformation was used for the percentage data:

$$
\text { germinatio } n \text { percentage }=\operatorname{arcsen} \sqrt{\frac{(\text { germinatio } n+1)^{2}}{100}}
$$

The factors species, ionic liquid (natural or degraded) and treatment were analyzed using one ANOVA statistical test. When significant interactions between the factors were detected, ANOVAs for each species were done. Duncan tests were performed to determine which treatments or species caused the differences detected.

\section{Results}

\section{Soil microcalorimetry}

Figure 2 shows the curves corresponding to microbial activity in soil under Pine with different doses of $\left[\mathrm{C}_{4} \mathrm{C}_{1} \mathrm{C}_{1} \mathrm{Im}\right][\mathrm{OTf}]$. In these curves thermal power $(\mu \mathrm{W})$ is plotted against time $(\mathrm{h})$. From these curves the total heat evolved during the process $(\Delta \mathrm{H})$, the peak time $\left(\mathrm{P}_{\mathrm{t}}\right)$ i.e. the time to reach the maximum of the peak, the peak height $\left(\mathrm{P}_{\mathrm{h}}\right)$, i.e. the power at the maximum of the peak and the total heat evolved up to the maximum, $Q_{t}(J)$, of the Power-time curve were calculated. The obtained values for each parameter are presented in Table 1.

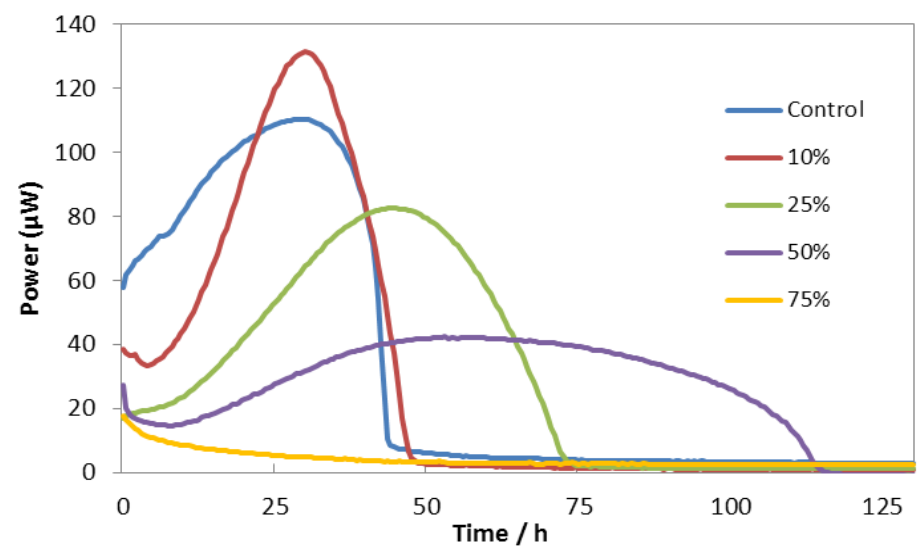

Figure 2. P-t curves corresponding to microbial activity in soil under Pine with different doses of $\left[\mathrm{C}_{4} \mathrm{C}_{1} \mathrm{C}_{1}\right.$ Im] [OTf].

Table 1. Characteristic microcalorimetric parameters corresponding to soil under Pine with different doses of $\left[\mathrm{C}_{4} \mathrm{C}_{1} \mathrm{C}_{1} \mathrm{Im}\right][\mathrm{OTf}]$ : total heat evolved during the process $(\Delta H)$; Peak 
time $\left(P_{t}\right)$, Peak height $\left(P_{h}\right)$ and the total heat evolved up to the maximum of the Powertime curve $\left(Q_{t}\right)(J)$.

\begin{tabular}{cccccc}
\hline Property & Control & $10 \%$ & $25 \%$ & $50 \%$ & $75 \%$ \\
\hline$\Delta H / \mathrm{J}$ & 14.17 & 12.56 & 13.04 & 11.99 & 1.57 \\
$P_{h} / \mu \mathrm{W}$ & 110.35 & 131.40 & 82.34 & 42.40 & - \\
$P_{t} / \mathrm{h}$ & 29.52 & 30.34 & 46.37 & 53.25 & 0 \\
$Q_{t} / \mathrm{J}$ & 9.66 & 7.37 & 7.63 & 4.96 & - \\
\hline
\end{tabular}

From a lineal fitting of the $\ln \mathrm{P}$ versus time, the microbial growth rate constant for each concentration of IL has been calculated [4]. It can be observed that this constant shows a lineal decreasing behaviour with concentration of IL, as it is shown in Figure 3.

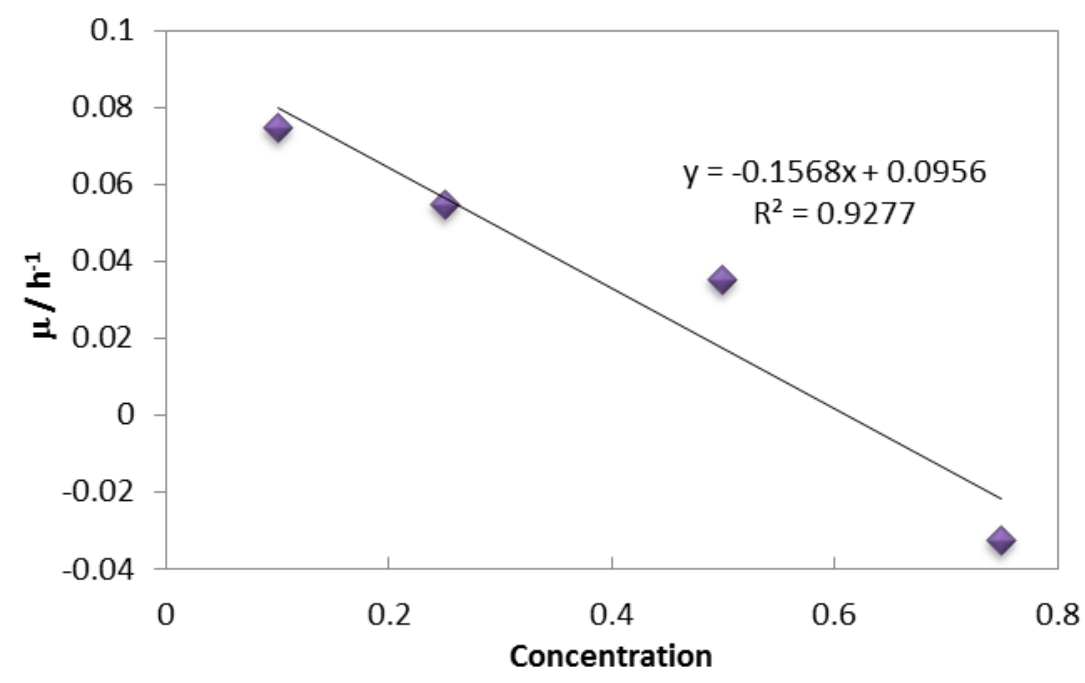

Figure 3. Fitting of the soil microbial growth rate versus concentration of $\left[\mathrm{C}_{4} \mathrm{C}_{1} \mathrm{C}_{1} \mathrm{Im}\right][0 \mathrm{OTf}]$.

From power time curves, data of the heat evolved during the experiments have been obtained and represented as "heat-time" curves in Figure 4.

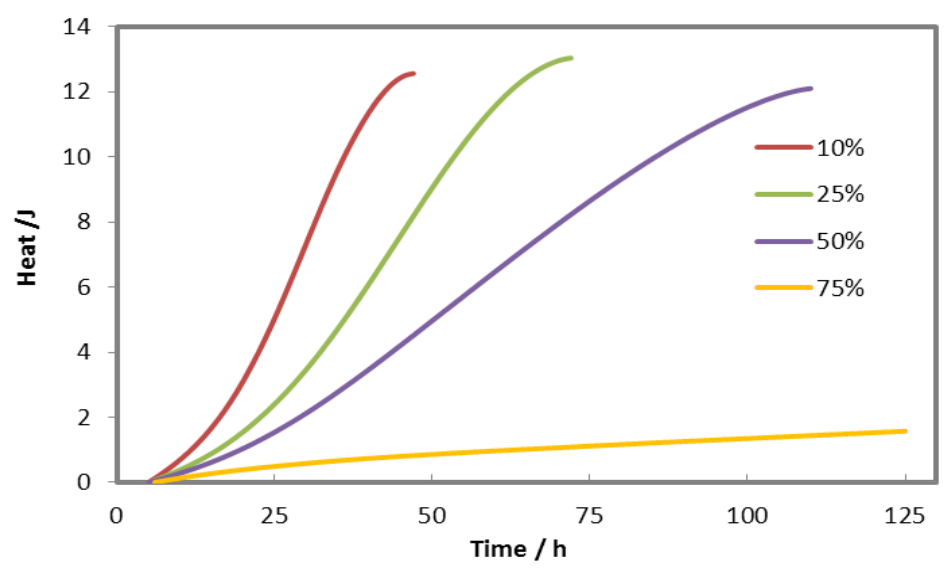

Figure 4. Heat-time curves for soil under Pine with different doses of [C $\left.{ }_{4} \mathrm{C}_{1} \mathrm{C}_{1} \mathrm{Im}\right][0 \mathrm{OTf}$. 
It can be seen that the slope of the lineal part of these curves decreases with the concentration of IL in the soil sample. From a lineal fitting of this part of the heat curve versus time, a numerical value of this slope, named parameter $\mathrm{dq} / \mathrm{dt}$, was obtained for each studied doses of $\left[\mathrm{C}_{4} \mathrm{C}_{1} \mathrm{C}_{1} \mathrm{Im}\right][\mathrm{OTf}]$.

Plotting dq/dt versus the doses of $\left[\mathrm{C}_{4} \mathrm{C}_{1} \mathrm{C}_{1} \mathrm{Im}\right][\mathrm{OTf}]$, a lineal decreasing behaviour can be observed, as it is shown in Figure 5, i.e. the same tendency that was observed in Figure 3 with $\mu$ versus the concentration of $\left[\mathrm{C}_{4} \mathrm{C}_{1} \mathrm{C}_{1} \mathrm{Im}\right][\mathrm{OTf}]$.

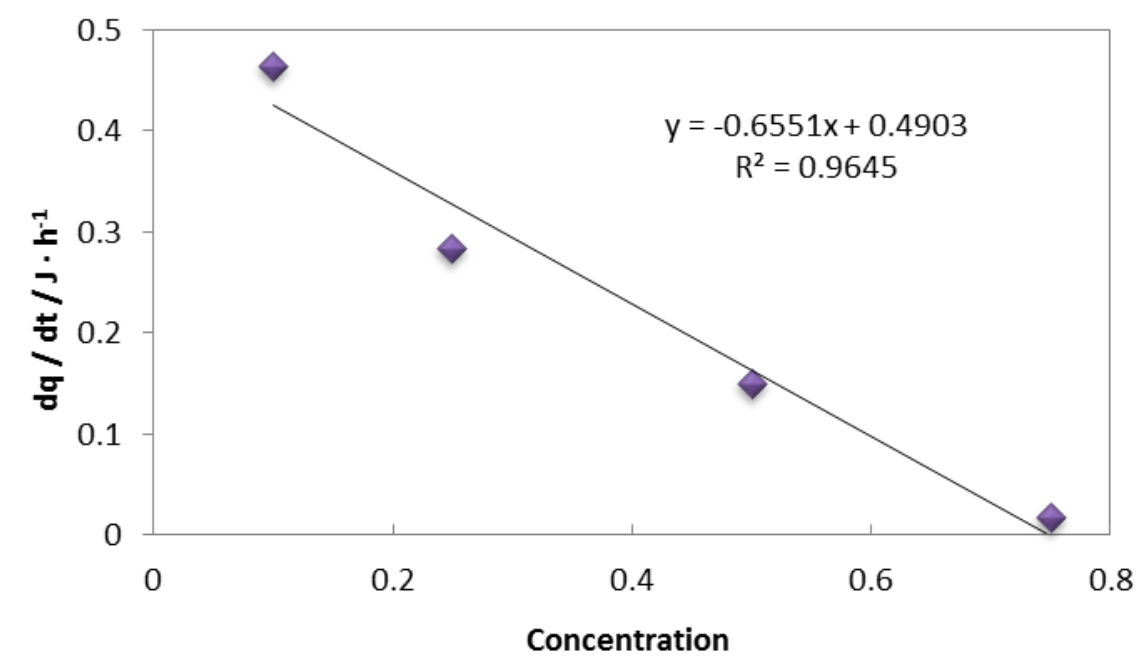

Figure 5. Fitting of the heat slope versus concentration of $\left[C_{4} C_{1} C_{1} I m\right][0 T f]$.

Following observations can be made from these analyses:

$\checkmark \quad$ P-t curves corresponding to the soil under Pine with doses of $10 \%$ and $25 \%$ of $\left[\mathrm{C}_{4} \mathrm{C}_{1} \mathrm{C}_{1} \mathrm{Im}\right][\mathrm{OTf}]$ are sharp and narrow if comparing to the higher doses of this IL in the same soil. This could be associated to an effect of promotion of growth in the soil at low concentrations of this IL, but complementary analysis should be done to assure this statement.

$\checkmark$ As the concentration of IL in the soil is increased:

- The beginning of the peak is delayed

- The shape of the P-t curve is flattened

- The peak height $\left(\mathrm{P}_{\mathrm{h}}\right)$ decreases and shifts to higher times, so the "total" growth is slower

- The microbial growth rate constant decreases which indicates that the exponential growth is faster as the doses of IL is lower

- The heat released in time, $\Delta H$, decreases

- The slope of the heat-time curves decreases

$\checkmark$ For doses of $75 \%$ in IL no significant growth is detected. 


\section{Germination response}

The percentages of germination obtained show big differences between the applied treatments, between both conditions of the ILs (natural or degraded) and also in the specific response of every species. The species that reaches the highest control germination percentage is $P$. sylvestris with $63 \%$, followed of E. globulus with $58 \%$ and P. radiata with $53 \%$; whereas the lowest value corresponds to P. pinaster, with $29 \%$ of control germination (Figure 6). [ $\left.\mathrm{C}_{4} \mathrm{C}_{1} \mathrm{C}_{1} \mathrm{Im}\right]$ [OTf] natural produces lethal effects in all the species with the highest tested dose, $10 \%$. Important reductions of the percentage of germination are observed with the dose of $1 \%$ against to the corresponding to control. The other two doses produce small variations on the percentage of germination against to the control. $\left[\mathrm{C}_{4} \mathrm{C}_{1} \mathrm{C}_{1} \mathrm{Im}\right][\mathrm{OTf}]$ degraded provokes similar effects on seeds than natural IL.

The ANOVA detected highly significant differences between the species $(\mathrm{P}<0.001)$ and between the treatments $(\mathrm{P}<0.001)$. The interaction species $\mathrm{x}$ treatment was also significant $(\mathrm{P}=0.001)$ which indicates a singular response of every species to the treatments. For this reason ANOVAs was performed for every species, detecting highly significant differences $(\mathrm{P}<0.001)$ between the treatments for all the species. According to Duncan's test, the effect of the doses $10 \%$ and $1 \%$ of the ILs (natural and degraded) reduce significantly the germination in all the species. Additionally, a slightly germination stimulation was detected in $P$. radiata with the treatment $0.01 \%$ of the natural IL.

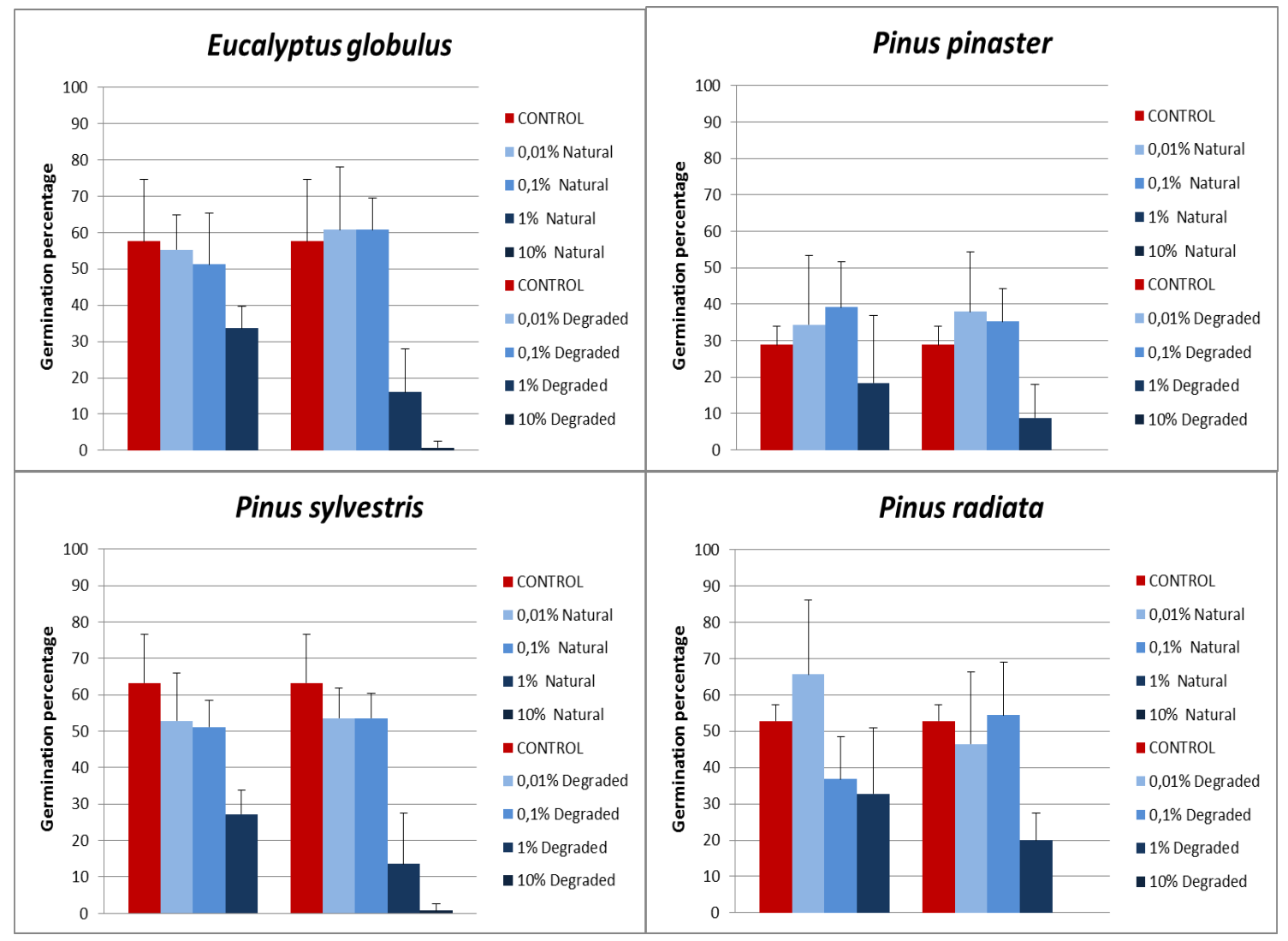

Figure 6. Germination percentages reached by E. globulus, P. pinaster, $P$. radiata and $P$. sylvestris with different treatments of the IL degraded and no degraded. 
Acknowledgments: Authors acknowledge the samples provided by Merck KGaA. This work was supported by the projects EM2013/031, AGL2013-48189-C2-2-R, the FEDER financing and Galician Network of ionic liquids (REGALIs) (Xunta de Galicia)

\section{References}

[1] B. Peric, J. Sierra, E. Martí, R. Cruañas, M.A. Garau, J. Arning, U. Bottin-Weber, S. Stolte, Journal of Hazardous Materials, 261 (2013) 99-105.

[2] S. Stolte, S. Steudte, A. Igartua, P. Stepnowski, Current Organic Chemistry, 15 (2011) 1946-1973.

[3] M. Petkovic, K.R. Seddon, L.P.N. Rebelo, C. Silva Pereira, Chemical Society Reviews, 40 (2011) 1383-1403.

[4] I. Barja, L. Núñez, Soil Biology and Biochemistry, 31 (1999) 441-447.

[5] L. Núñez-Regueira, J.A. Rodríguez-Añón, J. Proupín-Castiñeiras, O. Núñez-Fernández, M. Villanueva, Soil Biology and Biochemistry, 38 (2006) 115-124.

[6] O. Reyes, L. Trabaud, Plant Ecol, 202 (2009) 113-121. 